\title{
A Retrospective Study on The Prevalence of Fasciola Infection in Sheep and Goats at Slaughter and Associated Economic Losses from Condemnation of Infected Liver in Maiduguri Abattoir, Nigeria
}

\author{
MBAYA $^{1 *}$, A.W., SHINGU ${ }^{1}$, P. and LUKA ${ }^{1}$, J.
}

${ }^{1}$ Department of Veterinary Microbiology and Parasitology, Faculty of Veterinary Medicine, University of Maiduguri, P.M.B. 1069, Maiduguri, Nigeria Correspondence: E-mail: awmbaya@yahoo.com; Tel: +234 0803601174

\section{SUMMARY}

A retrospective study on the prevalence of fasciolosis among small ruminants (sheep and goats) slaughtered at Maiduguri, metropolitan abattoir and the associated economic losses from condemnation of infected liver were estimated between January 2004 - December 2009. Out of the 15,113 sheep and 9,617 goats examined during the period, $123(0.49 \%)$ and $70(0.28 \%)$ were infected with fasciolosis respectively. There was no statistical variation $(P>0.05)$ on the prevalence of infection between the two species of ruminants. However, according to age, out of the 3,959 young sheep and 4,417 young goats ( $<12$ months) examined, $20(0.13 \%)$ and $7(0.07 \%)$ were infected respectively. Similarly, out of the 11, 154 and 5, 200 adult sheep (>12 months) and goats examined, $103(0.68 \%)$ and $63(0.66 \%)$ were infected respectively. Among the sheep, the adults were found to be more infected than the young. Statistically, the difference was significant $(p<0.05)$. Meanwhile, among goats no statistical variation $(p>0.05)$ existed between age groups. According to sex, out of the 7, 097 male sheep and 4,839 male goats examined, 56(0.37\%) and 25(0.26\%) were infected with fasciolosis respectively. Similarly, out of the 8,016 female sheep and

4, 778 female goats examined, $67(0.44 \%)$ and $45(0.47 \%)$ were infected respectively. Among sheep, both male and female were equally infected ( $p>0.05$ ). The difference was not significant. According to season, both sheep and goats were more infected during the rainy than the dry season. The difference was statistically significant $(p<0.05)$. The monthly prevalence also showed peak infections in July and August for sheep and July for goats. The yearly financial loss in sheep due to liver condemnation for the period (2004-2009) was estimated at N 23, 616. 00 while that of goats was N 8, 960.00. In conclusion, the results show that fasciolosis affects both sheep and goats in Maiduguri, Nigeria and is a major source of liver condemnation in small ruminants in the area.

KEY WORDS: Retrospective study, Fasciola infection, Economic loss, Maiduguri

\section{INTRODUCTION}

Fasciolosis is one of the major causes of great economic losses due to liver condemnation in large ruminants (Soulsby, 1982; Radostitis et al., 1994) and small ruminant industry (Schillhorn vanveen, 1977; Ibrahim et al., 2001; Kamani et al., 2007; Okoli et al., 2000). Most of the reports were, based on data gathered passively from slaughterhouse records which shows that fasciolosis is common in sheep in Enugu, Nigeria (Okoli et al., 2000) and in Maiduguri, Nigeria (Kamani et al., 2007). The clinical entities of the acute and subacute forms are seen in animals of all ages and various nutritional states (Soulsby, 1982). However, the chronic form is the most common in ruminants and man and occurs when small numbers of metacercaria are ingested over a long period (Soulsby, 1982; Radostitis et al., 1994).

The course of the disease usually last as long as $2-3$ months, which ends in death, while the unthrifty ones are sold for meat (Ibrahim et al., 2001). The pathology of fasciolosis may be divided into hepatic fibrosis and hyperplasia colangitis (Dargie et al., 1974; Rushton and Murray, 1977). Migration of immature flukes in the liver produces migratory tracts within which, a traumatic destruction of liver parenchyma, 
haemorrhage and necrosis ensue (Soulsby, 1982). The tropical environment in association with the relative abundance of the moluscine intermediate host (Lymnia spp) propagates the redia, sporocyst and cercarial stages of the parasite (Peter, 1997). Although, a retrospective study of ovine fasciolosis was conducted for the period (1992-1997) in Maiduguri, Nigeria (Kamani et al., 2007) no comparative study between ovine and caprine fasciolosis nor its associated financial losses due to liver condemnation estimated was conducted. This study was therefore, designed to study the prevalence of ovine and caprine fasciolosis from 2004 - 2009 demographically and its associated financial losses following liver condemnation.

\section{MATERIALS AND METHODS Study area}

The Maiduguri Municipal Abattoir, where the study was conducted is located in Maiduguri, the largest urban city in Borno state, in the northeastern part of Nigeria (Udoh, 1981). Borno state lies between latitude $11^{\circ} 40^{\prime} \mathrm{N}$ and Longitude $13^{\circ} 05^{\prime} \mathrm{E}$ and $13^{\circ} 25^{\prime} \mathrm{E}$ within the Sahel Savannah, which consists of the sub-desert lands and the transition zones between the true desert (Sahara) and the Sahel with rainfall under $700 \mathrm{~mm}$. The rainy season lasts for a short time (3-4 months) from June to September. This is followed by a prolonged dry season from October - May (Udoh, 1981).

\section{Data collection}

Records of all diagnosed and confirmed cases of fasciolosis following meat inspection and condemnation of liver of sheep and goats from January 2004 to December 2009 were collated and analyzed. Demographic data regarding sex and age were considered.

\section{Estimation of financial loss}

The total number of liver condemned as unfit for human consumption during meat inspection was noted for sheep and goats. Financial losses in naira was subsequently based on a pilot study that showed a mean weight of $0.48 \mathrm{~kg}$ for sheep and $0.32 \mathrm{~kg}$ for goat livers, as well as a market price of $\mathrm{N}$
$400.00 / \mathrm{kg}$ of such offal in Maiduguri at the time of the study.

\section{Statistical analysis}

The Students $t$-test was used in pair wise comparison of prevalence rates and $p$ values less than 0.05 were, considered significant. A $2 x 2$ contingency table for analysis of relative risks and Chi-square for independence and trend were employed to give a measure of association between the variables (Maed and Curnow, 1983).

\section{RESULTS}

Table I shows the prevalence of fasciolosis among sheep and goats examined in Maiduguri, Metropolitan Abattoir for the period (2004-2009). Out of the 15, 113 sheep and 9, 617 goats examined, $123(0.49 \%)$ and $70(0.28 \%)$ were infected respectively with fasciolosis. For sheep, peak prevalence was noted in the rainy season months of July -August, while none was encountered in the month of May. Meanwhile, for goats, peak prevalence was noted in July with none in February and December (Fig. 1). There was no statistical variation $(p>0.05$ in the prevalence of infection between sheep and goats. Table II shows the prevalence of fasciolosis according to age and sex for the period. Out of the 3, 959 young sheep and 4, 417 young goats ( $<12$ months) examined, $20(0.13 \%)$ and $7(0.07 \%)$ were infected respectively.

It was also observed that out of the 11, 154 and 5, 200 adult sheep and goats examined, $103(0.68 \%)$ and $63(0.66 \%)$ were infected respectively. Between different age groups, the adult sheep were more infected than the young ones. The difference was statistically significant $(\mathrm{p}<0.05)$. Meanwhile among goats, there was no statistical variation (p $>0.05)$ between age groups. Similarly, out of the 7, 097 male sheep and 4, 839 male goats examined, 56(0.37\%) and 25(0.26\%) harboured fasciolosis. At the same time, out of the 8, 016 female sheep and 4, 778 female goats examined, 67(0.44\%) and 45(0.47\%) were infected respectively. Among sexes in the sheep, both male and female were equally infected ( $p>0.05)$, while among the goats, the female were more infected $(p<0.05)$ than the males. 
TABLE I: Prevalence of Fasciolosis among sheep and goats at slaughter in Maiduguri metropolitan abattoir for the period (2004-2009)

\begin{tabular}{|lcc|}
\hline Species & Total number examined & Total number infected $(\%)$ \\
\hline Sheep & 15,113 & $123(0.49 \%) \mathrm{a}$ \\
Goats & 9,617 & $70(0.29 \%) \mathrm{a}$ \\
Total & 24,730 & $193(0.78)$ \\
\hline
\end{tabular}

Superscripts in column did not differ significantly $(P>0.05)$

Table III shows the seasonal prevalence of fasciolosis among sheep and goats examined at the Maiduguri metropolitan abattoir for the period (2004-2009). Out of the 8,145 sheep and 5, 255 goats examined during the dry season, 23(0.15\%) and $10(0.10 \%)$ were respectively infected. In the rainy season, out of 6,968 sheep and 4 , 362 goats examined, $100(0.66 \%)$ and $60(0.62 \%)$ were infected with fasciolosis respectively. Between seasons, both sheep and goats were more infected $(\mathrm{p}<0.05)$ during the rainy season than in the dry season. For the period (2004-2009) in sheep, the total meat $(\mathrm{Kg})$ lost due to liver condemnation was estimated at 49.04 as compared to 22.4 for goats. Therefore, the total financial loss $(\mathrm{N})$ stood at 23,616 and 8, 960 for sheep and goats respectively (Table IV).

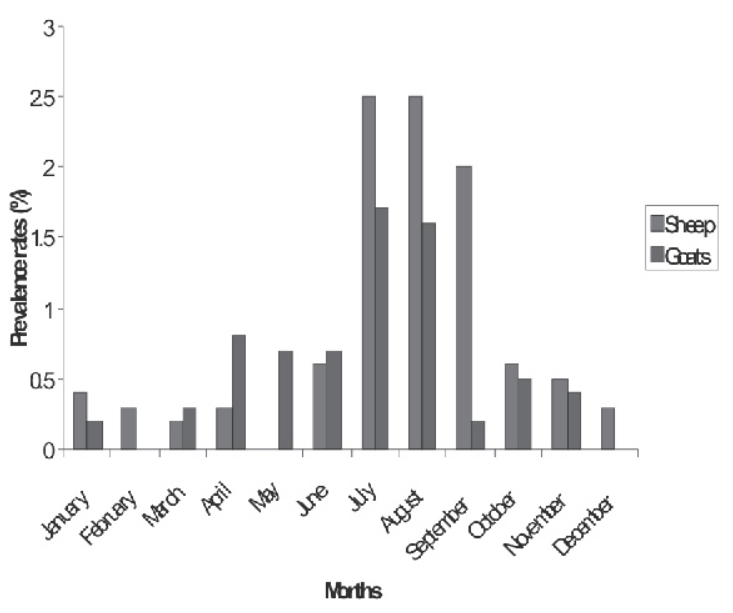

Fig. 1: Monthly prevalence of fasciolosis among sheep and goats at slaughter in Maiduguri metropolitan abattoir for the period (2004-2009).

TABLE II: Prevalence of Fasciolosis among sheep and goats at slaughter in Maiduguri metropolitan abattoir according to age and sex for the period (2004-2009)

\begin{tabular}{|ccccc} 
Parameters & \multicolumn{2}{c}{ Sheep } & \multicolumn{2}{c}{ Goats } \\
& No. Examined & No. Infected (\%) & No. Examined & No. Infected (\%) \\
Age Young (<12 months) & 3,959 & $20(0.13) \mathrm{a}$ & & \\
Adults & 11,154 & $103(0.68) \mathrm{b}$ & 4,417 & $7(0.07) \mathrm{a}$ \\
$\quad(>12$ months) & & & 5,200 & $63(0.66) \mathrm{a}$ \\
Total & 15,113 & $123(0.81)$ & 9,617 & $70(0.73)$ \\
Sex Male & 7,097 & $56(0.37) \mathrm{a}$ & 4,839 & $25(0.26) \mathrm{a}$ \\
Female & 8,016 & $67(0.44) \mathrm{a}$ & 4,778 & $45(0.47) \mathrm{b}$ \\
Total & 15,113 & $123(0.81)$ & 9,617 & $70(0.73)$
\end{tabular}

$a, b$ Superscripts in column differ significantly $(p<0.05)$ a,a Superscripts in column did not differ significantly $(p>0.05)$ 
TABLE III: Seasonal prevalence of Fasciolosis among sheep and goats at slaughter in Maiduguri, metropolitan abattoir for the period (2004-2009)

\begin{tabular}{|lcccc|}
\hline Seasons & \multicolumn{2}{c}{ Sheep } & \multicolumn{2}{c|}{ Goats } \\
& No Examined & No. Infected (\%) & No. Examined & No. Infected (\%) \\
\hline All seasons & 15,113 & $123(0.81)$ & 9,617 & $70(0.72)$ \\
Dry season & 8,145 & $23(0.15) \mathrm{a}$ & 5,255 & $10(0.10) \mathrm{a}$ \\
Rainy season & 6,968 & $100(0.66) \mathrm{b}$ & 4,362 & $60(0.62) \mathrm{b}$ \\
\hline
\end{tabular}

$a, b$ Superscripts in columns differed significantly $(p<0.05)$

TABLE IV: Yearly financial loss due to Fasciolosis among sheep and goats associated with liver condemnation in Maiduguri, metropolitan abattoir for the period (2004-2009)

\begin{tabular}{|c|c|c|c|c|}
\hline Species & Year & No. of liver condemned & Meat lost $(\mathrm{Kg})$ & Financial loss (N) \\
\hline Sheep & $\begin{array}{l}2004 \\
2005 \\
2006 \\
2007 \\
2008 \\
2009\end{array}$ & $\begin{array}{c}18 \\
20 \\
19 \\
17 \\
8 \\
41\end{array}$ & $\begin{array}{l}8.64 a \\
9.6 b \\
9.12 b \\
8.16 a \\
3.84 c \\
19.68 d\end{array}$ & $\begin{array}{l}3,456 a \\
3,840 a \\
3,648 a \\
3,264 a \\
1,536 b \\
7,872 c\end{array}$ \\
\hline & Total & 123 & 49,04 & 23,616 \\
\hline Goats & $\begin{array}{l}2004 \\
2005 \\
2006 \\
2007 \\
2008 \\
2009\end{array}$ & $\begin{array}{c}10 \\
7 \\
8 \\
18 \\
16 \\
11\end{array}$ & $\begin{array}{l}3.20 a \\
2.24 b \\
2.56 b \\
5.76 c \\
5.12 c \\
3.52 a\end{array}$ & $\begin{array}{l}1,280 a \\
896 b \\
1,024 a \\
2,304 c \\
2,048 c \\
1,408 a\end{array}$ \\
\hline & Total & 70 & 22.4 & 8,960 \\
\hline
\end{tabular}

\section{DISCUSSION}

Studies on the prevalence of fasciolosis due to Fasciola gigantica have been carried out in some parts of Nigeria (Ademola, 2003; Kamani et al., 2007). There is however, a general paucity of information regarding economic losses due to condemnation of liver in sheep and goats. In this study, both sheep and goats were infected, and the estimated economic loss due to liver condemnation was relatively higher in sheep than in goats. This could be because, sheep are more prone to the infection since they graze more often with cattle in areas with germinating pasture along riverbanks and flood plains where contact with metercarial-encysted grass blades is common. Meanwhile, the sahelian goats tend to roam freely around human dwellings in Maiduguri as they scavenge for shrubs and thistles.
The results also show that the adult sheep were more infected than the young ones. This agrees with the findings of Kamani et al., (2007). This is probably associated with the fact that young and adult sheep graze more or less together. The difference in infection rate may be more of immunity in one age group than in the other (Soulsby, 1982).

Similarly, the study revealed that female goats harboured more infection than their male counterparts. A Similar observation where female ruminants exhibited increased susceptibility to helminthosis was associated to hormonal activity, especially at pregnancy (Doyle, 1971; Schillhorn van veen, 1997; Soulsby, 1982; Ibrahim et al., 2001). This is likely the situation, since antemortem records for the period of the study showed that most of the female goats 
slaughtered within the period were at various trimesters of pregnancy.

Seasonal prevalence of fasciolosis among sheep and goats was significantly higher $(\mathrm{P}<0.05)$ during the rainy season as compared to the dry season. This is in consonance with the findings of Kamani et al. (2007) in Maiduguri but vary from that of Ademola (2003) who reported higher prevalence during the dry season in Oyo State, Nigeria. The climatic difference between the study areas especially, the duration of the rainy season and the higher relative humidity that prevail all year round in Oyo State (Ademola, 2003) may explain the seasonal variation in prevalence. Temperature, humidity and rainfall pattern are known to play an important role in the epidemiology of fasciolosis (Radostitis et al., 1994; Kessler, 1987; Ademola, 2003). It is expected, therefore, that the short rainy season in the arid-region of northeastern, Nigeria favour moluscine activity for a short period. Similarly, the arid zone of northeastern, Nigeria, where Maiduguri is located with its usual scarcity of grasses during the dry season causes livestock in the area to migrate to germinating pasture along fringes of the Lake Chad, river banks and flood plains where moisture support the germinating of grass blades that are often contaminated with encysted metacercaria.

\section{CONCLUSION}

It is therefore, concluded that that fasciolosis occur in sheep and goats in Maiduguri, Nigeria and is a major source of liver condemnation in small ruminants in the area.

\section{ACKNOWLEDGEMENTS}

The staff and management of Maiduguri metropolitan abattoir are highly appreciated for providing their records.

\section{REFERENCES}

ADEMOLA, I. (2003): Meteorological changes and their influence on the epidemiology of fasciolosis in food animals slaughtered in Oyo State. Nig. Vet. J., 24: 35-38.

DARGIE, J.D., ARMOUR, J., RUSHTON, B. and MURRAY, M. (1974): Immune mechanism in hepatic fibrosis in fasciolosis. In: Parasitic Zoonosis. (E.J.L. Soulsby Ed.) New York Academic Press: 240-271.

DOYLE, J.J. (1971): Immune responses to Fasciola hepatica. Res. Vet. Sci., 6: 527-528.

IBRAHIM, M.A., PATRICK, V.K. and ALHAJI, A.M. (2001): An analysis of the effect of socio-economic status of farmers and season variation on the marketing of $\mathrm{p} \mathrm{re} \mathrm{g} \mathrm{nan} \mathrm{t}$ does for meat in Borno State. Agro Satellite, 1:2-12.

KAMANI, J., YIDAWI, J.P., BUBA, S., DAHIRU, J.J. and BUKAR, M.D.Y. (2007): Seasonal incidence of ovine fasciolosis in Maiduguri, Borno State, Nigeria. An abattoir survey. In: Proceedings of the $44^{\text {th }}$ Annual Congress of the Nigerian Veterinary Medical Association: 222-225.

KESSLER, J.J. (1987): Sheep herding patterns in relation to environmental condition i $n$ land use in Dhamar Montane plains. RLIP communications 15, Ministry of Agriculture. Yemen Arabic Republic DHV consulting engineers, Amersfoort: 73-75.

MAED, R. and CURNOW, R.N. (1983): Statistical Methods in Agriculture and Experimental Biology. Chapman and Hall, London; 1-34.

OKOLI, I.C., AGOH, E.C., OKOLI, G.C., IDEMILI, G.C. and UMESIOBI, D.O. (2000): Bovine and caprine fascioliasis in Enugu State, Nigeria: Retrospective analysis of abattoir records (1993-1997) and six months prevalence study. Bull. Anim. Hlth. Prod. Afr. 48: 7-11.

RADOSTITIS, O.M., BLOOD, D.C. and GRAY, G.C. (1994): Veterinary Medicine. A Textbook of Diseases of Cattle, Sheep, Goats, Pigs and Horses. Bailliere Tindal, London; 35-67.

RUSHTON, B. and MURRAY, M. (1977): Hepatic pathology of a primary experimental infection of Fasciola hepatica in sheep. $J$. Comp. Pathol., 87: 459-470.

SCHILLHORN VAN VEEN T.W. (1997): Sense or nonsense? Traditional methods of a $\mathrm{n}$ im a 1 parasitic disease control. Vet. Parasitol., 71: 177-194.

SOULSBY, E. J. L. (1982): Helminths, Arthropods and Protozoa of Domesticated Animals. $7^{\text {th }}$ Edn. Bailliere Tindall and Company London; 800 - 809.

PETER, J.W. (1997): Sustainable helminth control of ruminants in developing countries. Vet. Parasitol., 71: 195-207.

UDOH, R.K. (1981): Geographical Regions in Nigeria. Heinemann Education Ltd, Ibadan; 1-24. 